\title{
PESAN-PESAN PENDIDIKAN IBADAH (TELAAH NOVEL SANG PENCERAH) KARYA AKMAL NASERY BASRAL
}

\author{
Ali Muttaqin, Normuslim \\ Pendidikan Agama Islam, Institut Agama Islam Negeri Palangka Raya \\ Email: alimutaqqin@gmail.com
}

Website : https://jurnal.uin-antasari.ac.id/index.php/ptkpend/index

Received: 10 Juni 2021; Accepted: 14 September 2021; Published: 14 September 2021

\begin{abstract}
:
The focus of this research to explore the message of worship education contained, this is an effort to see how the message of worship education that the author wants to convey to the readers about worship education. The approach used in finding data in this research is library research with the main stages of exploring data sources from various readings, both primary and secondary.After tracing the data, it will be analyzed using the data analysis method,find several messages of worship that the author wants to c onvey to readers such as messages of prayer, fasting, and shadaqah.
\end{abstract}

\section{Keywords: Message; Worship Education; Sang Pencerah Novel}

\begin{abstract}
ABSTRAK
Fokus penelitian ini menggali pesan pendidikan ibadah, hal ini sebagai usaha untuk melihat bagaimana pesan pendidikan ibadah yang ingin disampaikan pengarang kepada pembacanya tentang pendidikan ibadah. Pendekatan yang digunakan dalam mencari data pada penelitian ini adalah studi riset kepustakaan ( library research) dengan tahapan pokok yang menelusuri sumber-sumber data dari berbagai bacaan baik yang bersifat primer maupun yang bersifat skunder. Setelah penelusuran data dilakukan, maka akan dianalisis dengan menggunakan metode analisis data (content analysis). Hasil penelitian ini akan menemukan beberapa pesan ibadah yang ingin disampaikan pengarang kepada pembaca seperti pesan ibadah shalat, puasa, dan shadaqah.
\end{abstract}

Kata Kunci: Pesan; Pendidikan Ibadah; Novel Sang Pencerah

\section{Pendahuluan}

Novel Sang Pencerah adalah salah satu karya sastra. Didalamnya menceritakan tentang kehidupan Ahmad Dahlan dalam berinteraksi dengan lingkungan dan sesamanya. Novel Sang Pencerah ini sangat fenomenal karena syarat dengan pesan-pesan moral dan pesan-pesan pendidikan, yang jarang ditemukan karya-karya seperti ini (Rasyidin dan Nizar, 2000). Sang pencerah merupakan sebuah novel yang ditulis berdasarkan sebuah fakta sejarah tentang sosok dan kehidupan pahlawan nasional KH. Ahmad Dahlan yang kini lebih dikenal dengan tokoh pendiri Muhammadiyah, yang syarat akan pesan- pesan pendidikan Islam khususnya pendidikan ibadah (Arifin, 2020).

Ahmad Dahlan memandang bahwa ibadah merupakan bentuk penjagaan dan pemeliharaan hubungan manusia dengan penciptanya, Sedangkan amar ma'ruf dan nahi mungkar sebagai pola ibadah untuk menjaga hubungan manusia dengan sesama manusia (Ar-Rob'i, 2006). Ibadah kepada Allah Swt merupakan perantara atau wasilah terbesar dalam mendidik ruh, karena ibadah puncak merasa rendah diri di hadapan Allah Swt. Oleh sebab itu Pesan-pesan Pendidikan ibadah inilah yang menjadi ketertarikan peneliti untuk melakukan penelitian, akhirnya melahirkan sebuah realita dan implementasi dalam sebuah novel (Ilyas, 2001). 
adalah segenap gerak hidup, baik gerak

\section{Metode Penelitian}

Jenis penelitian ini adalah penelitian kepustakaan (library research), yaitu penelitian bahan-bahan kepustakaan/literatur yang berkaitan dengan masalah penelitian (Asiah, 2008). Untuk memperoleh data, penulis menggunakan sumber yang langsung berkaitan dengan objek penelitian yaitu novel Sang Pencerah karya Akmal Nasery Basral (sumber primer) dan sebagai sumber sekunder penulis merujuk kepada bahan-bahan yang relevan dengan penelitian ini (Muriah, 2008). Pengumpulan data dilakukan dengan teknik survey kepustakaan yaitu mengadakan survei bahan kepustakaan untuk mengumpulkan bahanbahan, dan studi literatur yakni mempelajari bahan-bahan yang berkaitan dengan objek penelitian. Pengolahan data dilakukan dengan editing, klasifikasi, dan interpretasi (Bazamul, 2007). Dalam menganalisis data, penulis menggunakan metode analisis isi (content analysis) yaitu menganalisis atau menguraikan isi atau pesan yang terkandung dalam novel Sang Pencerah.

\section{Hasil Penelitian}

Pendidikan Ibadah ialah upaya pembinaan untuk bertaqarrub (mendekatkan diri) kepada Allah dengan jalan mentaati segala perintah-Nya, menjauhi larangan-Nya, dan mengamalkan segala yang diizinkan Allah. Menurut ulama tauhid, ibadah adalah mengesakan Allah Swt dan merendahkan diri serta menundukkan jiwa setunduk-tunduknya kepada Allah. Pengertian ini didasarkan pada firman Allah surah An-Nisa (4) ayat 36.

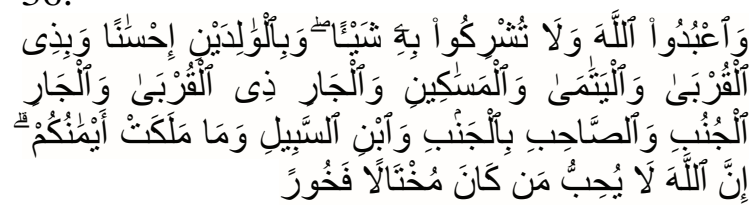

Adapun menurut para fuqaha, ibadah adalah segala ketaatan yang dikerjakan untuk mencapai keridhaan Allah Swt dan mengharap pahala-Nya di akhirat. Dalam arti yang lebih luas, ibadah hati, gerak lidah, gerak pikiran, maupun gerak anggota badan lainnya, yang ditujukan untuk meraih keridhaan Allah. (Nanang Gojali : 2004, 155). Ibadah dalam arti luas itu sejalan dengan pendapat Ibnu Taimiyah yang menjelaskan bahwa ibadah adalah nama yang mencakup segala sesuatu yang disukai dan diridhai oleh Allah dalam bentuk ucapan dan perbuatan, baik yang lahir maupun batin seperti shalat, puasa dan haji dan sebagainya. (Ismail Muhammad Syah: 1992, 173).

Ibadah menurut ajaran Islam terbagi menjadi dua, pertama, ibadah khusus atau ibadah mahdah, yaitu ibadah yang ketentuan pelaksanaannya telah ditetapkan oleh Allah dan dijelaskan oleh Rasul-Nya. Kedua, ibadah umum atau 'ammah, yaitu semua perbuatan yang mendatangkan kebaikan kepada diri sendiri dan orang lain, serta dilaksanakan dengan niat ikhlas kepada Allah Swt. (Muhammad Daud Ali: 2000, 247).

Kalau ditinjau dari segi bentuk dan sifatnya ibadah terbagi kepada lima macam, yaitu:

1. Ibadah dalam bentuk perkataan atau lisan, seperti berzikir, berdo'a, tahmid, dan membaca Alquran.

2. Ibadah dalam bentuk perbuatan yang tidak ditentukan bentuknya, seperti membantu atau menolong orang lain, jihad, dan lain sebagainya.

3. Ibadah dalam bentuk pekerjaan yang telah ditentukan wujud perbuatannya, seperti shalat, puasa, zakat, dan haji.

4. Ibadah yang tata cara dan pelaksanaannya berbentuk menahan diri, seperti puasa, iktikaf, dan ihram.

5. Ibadah yang berbentuk menggugurkan hak, seperti memaafkan orang lain yang telah melakukan kesalahan terhadap dirinya dan membebaskan seseorang yang berutang kepadanya. (Ahmad Thib Raya dan Musdah Mulia: 2003, 138-139). 
Jurnal PTK dan Pendidikan

Vol. 7, No. 1, Januari - Juni 2021 (77-82)

Di dalam Alquran kata ibadah disebutkan sebanyak 278 kali, (Abuddin Nata : 1996, 89). salah satunya sebagaimana yang terdapat dalam Alquran surah Adz-Dzariyat (51) ayat 56.

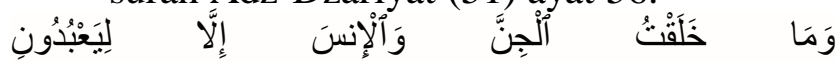

dan surah Al-Hajj (22) ayat 41.

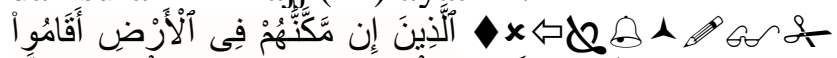

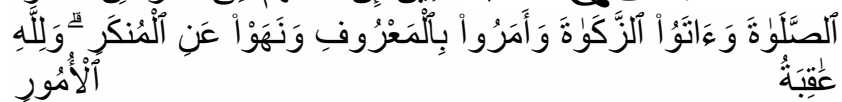

Dalam surah Adz-Dzariat ayat 56 di atas menjelaskan bahwa tujuan diciptakannya manusia dan jin adalah untuk beribadah kepada Allah Swt. Sedangkan dalam surah Al-Hajj ayat 41 menjelaskan tentang pola ibadah kepada Allah, dimana shalat dan zakat sebagai representasi dari pola ibadah khusus untuk menjaga dan memelihara hubungan manusia dengan penciptanya. Sedangkan amar ma'ruf dan nahi mungkar sebagai pola ibadah umum untuk menjaga hubungan manusia dengan sesama manusia yang kemudian diejewantahkan dalam ketentuan-ketentuan hukum mu'amalah, jinayah, dan siyasah.

Ibadah kepada Allah Swt merupakan perantara atau wasilah terbesar dalam mendidik ruh, karena ibadah puncak merasa rendah diri di hadapan Allah Swt. (Ali Abdul Halim Mahmud: 1995, 17). Abul A'la Maududi mengemukakan tentang luasnya lapangan ibadah dalam Islam sebagai berikut:

Dalam novel Sang Pencerah penulis menemukan beberapa kutipan yang berkenaan dengan pendidikan ibadah, antara lain:

1. Shalat

Ajaran Agama Islam yang harus dipelajari setelah seseorang mengucapkan kalimat syahadat adalah ibadah shalat. Karena bukti dari keimanan tersebut harus diaplikasikan dengan tingkah laku berupa ibadah shalat. Dalam shalat ini setiap muslim berinteraksi dengan Allah Swt, dan melalui shalat pendakian spiritual dapat mencapai puncaknya. (Ali, 2000)
Dalam novel Sang Pencerah karya Akmal banyak di temukan kutipan cerita yang membahas masalah shalat.

a. Kutipan pertama

"Mengapa kita harus lebih awal untuk datang untuk shalat Jum'at, Darwis?"

Ini salah satu cara bapak untuk menguji lagi ingatanku tentang materi yang pernah beliau ajarkan, tanpa membutuhkan waktu tersendiri (Darban, 2010). Maka aku kutip sebuah hadits tentang itu yang sangat kuhafal. "Diriwayatkan dari Abu Hurairah ra, bahwa Rasulullah Saw pernah bersabda: "Siapa yang mandi pada hari Jumat seperti cara mandi junub, kemudian pergi seawal mungkin untuk mengerjakan shalat Jumat, seolah dia berkurban seekor unta. Siapa yang pergi untuk melaksanakan shalat Jum'at pada waktu yang kedua, maka seolah dia berkurban seekor sapi. Siapa yang pergi pada waktu yang ketiga, maka seolah dia berkurban seekor kambing. Siapa yang pergi pada waktu yang keempat, maka dia seolah berkurban seekor ayam. Siapa yang pergi pada waktu yang kelima, maka seolah dia berkurban sebutir telur. Apabila imam sudah berada di atas mimbar, para malaikat berkumpul untuk mendengarkan khutbahnya. (Akmal Nasery Basral: 2010, 60).

Kutipan pertama ini berkenaan dengan shalat jum'at. Dalam shalat jum'at kita disunnahkan untuk mandi sebagaimana mandi junub kemudian berangkat ke rumah Allah (baca; masjid) seawal mungkin. Karena dalam sebuah hadits disebutkan bahwa orang yang pertama datang ke masjid untuk menunaikan shalat jum'at, maka seolah dia telah berkorban seekor unta. Namun siapa yang pergi untuk melaksanakan shalat jum'at pada waktu yang kedua, maka seolah dia berkorban seekor sapi. Siapa yang pergi pada waktu yang ketiga, maka ia seolah berkorban seekor kambing, dan seterusnya.

b. Kutipan kedua 
"Assalamu'alaikum." Aku menyapa mereka, yang mereka balas dengan anggukan hormat tanpa membalas salam.

"Kelihatannya capek sekali." Aku melanjutkan pertanyaan.

"Iya Kiai. Kami masih belum dapat pembeli meski sudah jalan desa-desa."

"Ikhtiar terus bapak-bapak, jangan mudah menyerah. Tapi apakah sudah diimbangi dengan shalat? Minta pertolongan Allah?”

pedagang itu saling tatap, tak ada yang menjawab pertanyaanku. "Sekarang sudah masuk waktu asar.Mari kita shalat berjamaah, insya Allah nanti berkah."

. (Akmal Nasery Basral: 2010, 191-192).

Dalam kutipan ini menggambarkan tentang perlunya ikhtiar yang diimbangi dengan ibadah, seperti ibadah shalat. Setiap usaha harus disertai dengan permohonan kepada Allah agar usahanya itu berhasil, salah satunya dengan shalat. Hal ini sebagaimana tergambar dalam surah Al-Jumuah (62) ayat 10.

c. Kutipan ketiga

"Begini, Sudja. Aku sudah menulis sebuah surat untuk dr. Wahidin. Bisakah kamu sampaikan surat itu kepada beliau melalui Mas Joyosumatro?"

"Tentu, kiai. Mana suratnya?" tanya Sudja bersemangat.

"Nanti saja, kita shalat dulu," kataku sambil menepuk-nepuk bahunya. "surat bisa menunggu."

.” (Akmal Nasery Basral: 2010, 312).

d. Kutipan keempat

"Terima kasih Sanggidu. Menurutku itu memang nama yang bagus. Tapi nanti malam aku harus shalat istikharah dulu (Darmawan, 2011).

Shalat istikharah adalah shalat untuk meminta petunjuk yang baik. Umpamanya seseorang akan mengerjakan suatu pekerjaan yang penting, sedangkan ia masih ragu-ragu, apakah pekerjaan itu baik untuk dia atau tidak. Ketika itu disunnahkan baginya untuk shalat istikharah dua rakaat, sesudah itu berdoa kepada Allah untuk minta petunjuk atas pekerjaan yang masih diragukannya itu (Atmaja, 2008). Dari beberapa kutipan di atas ada beberapa pesan pendidikan Islam yang disampaikan Akmal melalui novel Sang Pencerah ini, yaitu:

1) Sebelum menghadap Allah dalam shalat seseorang terlebih dahulu harus bersih dan suci dari hadats dan najis, baik itu pakaian dan tempat shalat.

2) Ketika seseorang dihadapkan pada satu masalah atau pada satu pilihan yang membuatnya bimbang dan ragu untuk memilih, maka hendaklah minta petunjuk dengan Allah melalui shalat istikharah.

3) kewajiban kepada Allah harus menjadi prioritas atau didahulukan dibandingkan kewajiban dengan manusia yang bisa untuk ditunda.

4) Untuk menghadap Allah, manusia dituntut untuk memakai yang terbaik.

5) Shalat adalah suatu ibadah yang harus dilaksanakan secara khusu hanya ingat kepada Allah.

2. Ibadah Puasa

puasa ialah menahan dan mengendalikan diri dari makan, minum dan hubungan seksual mulai dari terbit fajar sampai tenggelam matahari, dengan niat menjalankan perintah Allah untuk memperoleh ridha-Nya.

Menurut cendikiawan muslim Nurcholish Madjid, puasa adalah satu-satunya ajaran private dalam agama Islam (Chirzin: 2011, 18). Ajaran-ajaran lain seperti shalat, zakat dan haji, dilaksanakan dengan cara kolektif, diperlihatkan kepada khalayak umum sebagai pembelajaran positif, tetapi puasa dikerjakan secara pribadi dan tidak dipublikasikan (Bahsani, 2007).

a. Kutipan pertama

Aku merasa cukup mengerti bahwa persiapan dan kebersihan ruhani memasuki bulan suci ramadhan memang perlu. Sama saja seperti kita harus dalam keadaan suci ketika akan memasuki langgar atau masjid, begitu juga seharusnya kondisi ruhani 
ketika akan memasuki bulan suci. (Chirchin, 2011).

b. Kutipan kedua

"Wis, agama itu harus diajarkan dengan lemah lembut," jawab seorang anggota takmir lainnya." Tradisi ini bisa menjadi cara yang baik untuk menyampaikan ajaran agama."

Darwis.

"Tetapi itu berbahaya," sanggah Mas

"Berbahaya bagaimana?"

"Misalnya seperti pedusan dan ruwatan memasuki ramadhan itu. Banyak masyarakat yang menyangka wajib hukumnya melakukan pedusan dan ruwatan, sementara pada saat bulan suci sekarang sendiri kalian lihat sendiri di pasar, banyak yang tidak puasa. Padahal justru puasa itu yang wajib dilakukan, bukan pedusan," kata Darwis. (Firmansyah, 2011).

Dari cerita di atas, Akmal menyampaikan sebuah pesan penting mengenai ibadah puasa, yaitu:

1) Sebelum memasuki bulan puasa atau sebelum memulai puasa maka perlu diperhatikan kebersihan rohani atau kebersihan hati.

2) Bulan puasa atau bulan ramadhan harus disambut dengan penuh kegembiraan.

3) Mengerjakan puasa ramadhan menjadi berat manakala seseorang itu tidak terbiasa melakukan puasa sunnah.

4) Puasa menjadi wajib ketika bulan ramadhan tiba, sebagaimana firman Allah dalam surah Al-Baqarah (2) ayat 183.

\section{Ibadah Sedekah}

Manusia umunya gemar menumpuk atau menimbun harta. Namun mungkin tak pernah disadari bahwa harta mereka yang hakiki adalah yang disuguhkan pada kebaikan, salah satunya dengan mengeluarkan untuk sedekah. Sedekah merupakan salah satu perkara paling agung yang disyariatkan oleh Allah, dan memotivasi hamba-Nya untuk mengharap pahala dari sedekah tersebut (Fajar, 2008). Dalam novel Sang Pencerah ada beberapa kutipan yang berkenaan dengan sedekah, sebagaimana tertera di bawah ini.

a. Kutipan pertama

Aku pernah bertanya kepada bapakku, bagaimana caranya Kiai Hamid bisa begitu sering mengadakan makanan bersama padahal di mataku beliau terlihat tidak kaya,

"Itulah salah satu rahasia untuk tidak pernah kekurangan," ujar bapak. "Dengan banyak memberi."

"Iya, Bapak.. Tapi dari mana kemampuan bersedekah itu datang kalua kita masih hidup berkekurangan

"Susah dijelaskan dengan akal pikiran biasa Wis," kata bapak. "namun jika kita punyak niat akan dimudahkan. (Hariri, 2010).

b. Kutipan kedua

Sebaiknya Uang buat pembuatan sesajen itu bisa dimanfaatkan sebagai sedekah bagi fakir miskin sehingga hasilnya juga akan lebih jelas." (Kinayati, 2006).

Dari kutipan di atas, Akmal menyampaikan pesan pendidikan Islam tentang sedekah, yaitu:

1) Orang yang selalu membantu meringankan beban orang lain seperti melalui sedekah maka Allah akan memudahkan rezeki baginya.

2) Pada hakekatnya bersedekah itu bukan mengurangi harta seseorang tapi sebaliknya kehidupannya akan tercukupi.

3) Uang atau materi yang di keluarkan lebih baik digunakan untuk bersedekah kepada orang yang membutuhkan seperti pakir miskin dan anak yatim sehingga hasilnya lebih jelas.

Bersedekah tidak tergantung pada harta atau uang, tidak terikat pada segala yang berbentuk materi (Nasir, 2010). Bahkan mengucapkan tasbih, tahmid, dan tahlil pun merupakan bagian dari sedekah.

\section{Kesimpulan}

Pendidikan Ibadah yang terkandung di dalam Novel Sang Pencerah, seperti pentingnya Sholat, Puasa, dan bersedekah. adalah sebagai 
Jurnal PTK dan Pendidikan

Vol. 7, No. 1, Januari - Juni 2021 (77-82)

bukti keimanan seseorang terhadap Allah dan juga sebagai sarana utama yang ampuh untuk berinteraksi sembari menyandarkan semua harapan dan pengampunan atas tingkah laku didunia. Sebaliknya puasa dan sedekah sebagai bentuk pencucian jiwa dari segala bentuk kesombongan, iri dll.

\section{Daftar Pustaka}

Ali, Muhammad Daud, Pendidikan Agama Islam, Jakarta: Raja Grafindo Persada, 2000.

Al-Rasyidin dan Samsul Nizar, Filsafat Pendidikan Islam: Pendekatan Historis, Teoritis dan Praktis, Jakarta: Ciputat Press, 2005.

Arifin, M. Syamsul, "Komparasi Pemikiran K.H Ahmad Dahlan dan K.H Hasyim Asy'ari tentang Pendidikan Islam". http://lib.uinmalang.ac.id/files/thesis/introduction/06 110113.pdf, 16 September 2011

Ar-Rob'i, Kholid bin Sulaiman, Min Ajabi Sha Shodaqoh, Penerjemah, Abu Hanan Dzakiyya, Shodaqoh Memang Ajaib. Solo, Wacana Ilmiah Press, 2006.

Asiah, Siti, "Konsep Konvergensi Pendidikan Ditinjau Dari Ayat-Ayat Al-Qur'an". Al-Ulum: Jurnal Studi-Studi Islam Interdisipliner, Vol. 8, No.1 Juni 2008.

Atmaja, Isngadi Marwah, "Jika Kiai Dahlan Jadi Iklan Parpol". Suara Muhammadiyah: Meneguhkan dan Mencerahkan, Edisi No 22/Th. Ke-93, 16-30 November 2008.

Bahsani, Muhammad, Al-Shalat Hayat. penerjemah Tiar Anwar dan Reni Kurnaesih dengan judul Shalat Sebagai Terapi Psikologi. Bandung, Mizan, Cet. ke-1, 2007

Bazamul, Muhammad bin Umar bin Salim, AtTarjih fi Masaa'il At-Thaharah wa AshShalah, Penerjemah Ali Nur dengan judul Ensiklopedia Tarjih Masalah Thaharah dan Shalat. Jakarta, Darus Sunnah, Cet. ke-1, 2007

Chirzin, Muhammad, "Puasa dan Perolehannya dalam Al-Quran (1)," Suara
Ali Muttaqin, Normuslim

Muhammadiyah: Meneguhkan dan Mencerahkan, No. 14/Th. Ke-96, 16-31 Juli 2011.

Darban, Ahmad Adaby, Sejarah kauman menguak identitas kampung

Muhammadiyah. Yogyakarta, Surya Sarana Grafika, Cet ke-1. 2010.

Darmawan, Muhammad Arifin, "Studi Terhadap Metode Pendidikan Islam KH. Ahmad Dahlan Dalam Novel Sang Pencerah". http://etd.eprints.ums.ac.id/12423/1/2.H alaman_Depan.pdf, 15 September 2011.

Fajar, A. Malik, "Filosofi Pendidikan Muhammadiyah". Suara Muhammadiyah: Meneguhkan dan Mencerahkan, Edisi No 19/Th. Ke-93, 1-15 Oktober 2008.

Firmansyah, Novan Bagus, "Sabar Sebagai Kunci Sukses". Suara Muhammadiyah: Meneguhkan dan Mencerahkan, No. 23/Th. Ke-96, 1-15 Desember 2011

Gojali, Nanang, Manusia, Pendidikan dan Sains Dalam Perspektif Tafsir Hermeneutik, Jakarta: Rineka Cipta, 2004.

Hariri, Didik L. Jejak Sang Pencerah; Sebuah Novel Biografi [Ahmad Dahlan]. Jakarta, Best Media Utama, Cet. ke-1, 2010

Ilyas, Yunahar, Kuliah Akhlaq. Yogyakarta, Lembaga Pengkajian dan Pengamalan Islam, Cet. ke-4, 2001.

Kinayati, "Pesona Karya Sastra Dalam Pendidikan dan Pengajaran", dalam Jurnal Pendidikan dan Kebudayaan, tahun ke-12 No. 063, November 2006.

Muri'ah, Siti, "Pendidikan dalam Perspektif Islam Konsepsi dan Operasionalisasinya", Jurnal Ilmiah Manahij: Berpikir Kritis Transformatif, Vol. 1, No. 1, Mei 2008.

Nasir, M. Ridlwan, Mencari Tipologi Format Pendidikan Ideal Pondok Pesantren di Tengah Arus Perubahan, Yogyakarta: Pustaka Pelajar, 2010.

Nata, Abuddin, Al-Qur'an dan Hadits: Dirasah I slamiyah I, Jakarta: Raja Grafindo Persada, 1996. 